\title{
Molecular analysis of partial VP-2 gene amplified from rectal swab samples of diarrheic dogs in Pakistan confirms the circulation of canine parvovirus genetic variant CPV-2a and detects sequences of feline panleukopenia virus (FPV)
}

\author{
Nisar Ahmed ${ }^{1 \dagger}$, Adeel Riaz $^{1 \dagger}$, Zahra Zubair ${ }^{1}$, Muhammad Saqib ${ }^{4}$, Sehrish ljaz ${ }^{1}$ \\ Muhammad Shah Nawaz-Ul-Rehman ${ }^{1}$, Ahmed Al-Qahtani ${ }^{2,3}$ and Muhammad Mubin ${ }^{\text {* }}$
}

\begin{abstract}
Background: The infection in dogs due to canine parvovirus (CPV), is a highly contagious one with high mortality rate. The present study was undertaken for a detailed genetic analysis of partial VP2 gene i.e., 630 bp isolated from rectal swab samples of infected domestic and stray dogs from all areas of district Faisalabad. Monitoring of viruses is important, as continuous prevalence of viral infection might be associated with emergence of new virulent strains.

Methods: In the present study, 40 rectal swab samples were collected from diarrheic dogs from different areas of district Faisalabad, Pakistan, in 2014-15 and screened for the presence of CPV by immunochromatography. Most of these dogs were stray dogs showing symptoms of diarrhea. Viral DNA was isolated and partial VP2 gene was amplified using gene specific primer pair Hfor/Hrev through PCR. Amplified fragments were cloned in pTZ57R/T (Fermentas) and completely sequenced. Sequences were analyzed and assembled by the Lasergene DNA analysis package (v8; DNAStar Inc., Madison, WI, USA).
\end{abstract}

Results: The results with immunochromatography showed that 33/40 (82\%) of dogs were positive for CPV. We were able to amplify a fragment of $630 \mathrm{bp}$ from 25 samples. In 25 samples the sequences of CPV-2a were detected showing the amino acid substitution Ser297Ala and presence of amino acid (426-Asn) in partial VP2 protein. Interestingly the BLAST analysis showed the of feline panleukopenia virus (FPV) sequences in 3 samples which were already positive for new CPV-2a, with 99\% sequence homology to other FPV sequences present in GenBank.

Conclusions: Phylogenetic analysis showed clustering of partial CPV-VP-2 gene with viruses from China, India, Japan and Uruguay identifying a new variant, whereas the 3 FPV sequences showed immediate ancestral relationship with viruses from Portugal, South Africa and USA. Interesting observation was that CPV are clustering away from the commercial vaccine strains. In this work we provide a better understanding of CPV prevailing in Pakistan at molecular level. The detection of FPV could be a case of real co-infection or a case of dual presence, due to ingestion of contaminated food.

Keywords: Canine parvovirus, Feline panleukopenia virus, Coinfection, VP2 gene and phylogenetic analysis

\footnotetext{
* Correspondence: mmubin@uaf.edu.pk

${ }^{\dagger}$ Equal contributors

${ }^{1}$ Virology Lab, Center of Agricultural Biochemistry and Biotechnology (CABB),

University of Agriculture, PO Box 38040, Jail road, Faisalabad 38000, Pakistan

Full list of author information is available at the end of the article
} 


\section{Background}

Canine parvovirus-2 (CPV-2) is a single stranded (ss) DNA virus that is the most dreadful enteropathogen causing myocarditis and acute hemorrhagic gastroenteritis in dogs and young pups while Feline panleukopenia is a disease of cats caused by a highly contagious virus i.e., feline panleukopenia virus (FPV) [1].

CPV belongs to family Parvoviridae within subfamily Parvovirinae under the genus Protoparvovirus, as a viral variant of Carnivore protoparvovirus 1 species along with other variant like FPV, mink enteritis virus (MEV) and raccoon parvovirus (RaPV) [2]. After CPV-2 emergence occurred, its further antigenic variants arose quickly in the field, CPV-2a (showing Met87Leu, Asn375Asp, Ile101Thr and Val555Ile amino acid variations) and CPV-2b (VP2 protein showing residue 426 changed from Asn426Asp and then from Asp426Glu in the CPV-2b and CPV-2c antigenic variant strains, respectively. However, as the strains CPV-2b and CPV2c differ from CPV-2a by only one amino acid position (VP2 residue 426), they are not considered as distinct subtypes but only dominant variants of CPV- 2a [3, 4]. Antigenic variants, CPV-2a and CPV-2b divergence occurred from the CPV-2 strain due to changes in 5-6 amino acids in the antigenically important VP2 capsid region and in regaining the ability to infect feline cells in vitro and cats in-vivo again, while providing better adaptation to the canine host. CPV and FPV are two closely related viruses, causing disease in respective hosts, but new variants of CPVs have acquired the feline host range allowing them to infect both cats and dogs $[5,6]$, whereas the original CPV-2 does not replicate in cats. There are many studies showing that parvoviruses have a considerable degree of variability and that several viral variants can be detected simultaneously in an infected animal i.e., co-infection [1,7-10]. Amplification of partial VP2 gene and subsequent sequencing of the PCR products, where many important informative amino acids reside, would give definitive antigenic and genetic difference between the original CPV-2, its variants, and the vaccine strains [11]. As mutation and recombination in VP2 gene influence the host range and affinity of receptor binding [12], it becomes important for researchers to sequence VP2 encoding gene for better and precise identification of emerging strains, their relationship with vaccine strains, and also to understand the evolutionary pattern of CPV strains in the field. For the purpose of identification of $\mathrm{CPV}$, there are quite a few published papers where researchers have used partial VP2 gene sequence to report CPV $[13,14]$.

There is a recent study involving partial VP2 gene and amino acid analysis, where phylogenetic analysis had shown the circulation of heterogeneous CPV-2a strains in dog population in Pakistan. These strains shared high level of identity with Chinese strains [14]. The present study was undertaken for more detailed genetic analysis of partial VP2 gene sequences obtained from dogs and for possible co-infection of different parvoviruses, covering all areas of district Faisalabad. In this study we have reported phylogenetic and sequence analysis of two viruses i.e., CPV and FPV detected in dogs. The presence of a new CPV-2a variant was identified. The main objective of the study was to detect and genetically characterize prevalent parvoviruses circulating in Faisalabad, Pakistan.

\section{Methods}

\section{Clinical samples}

A total of 40 fecal samples/rectal swabs were collected from suspected dogs i.e., domestic as well as stray dogs from Veterinary Teaching Hospital, Department of Clinic Medicine and Surgery, University of Agriculture Faisalabad Pakistan and Civil Veterinary Hospital Faisalabad regardless of their vaccination status, as it was not available. In Pakistan more than $90 \%$ dogs are stray dogs with no vaccination what so ever. The samples were collected from dogs from different areas of Faisalabad district over the period of two years, (2014 and 2015). Five fecal samples/ rectal swabs were collected from healthy dogs as negative control. The collected samples were emulsified in $0.1 \mathrm{M}$ PBS and centrifuged at $3000 \mathrm{~g}$ for $10 \mathrm{~min}$ at $4 \mathrm{C}$. The supernatant was used for further analysis.

\section{Qualitative detection of CPV antigens in feces of dogs}

All the collected samples were checked for CPV Ag with the help of FASTest PARVO Strip (https://jfa.no/produkt/ fastest-parvo-strip-2stk/), according to the instructions of manufacturer).

\section{DNA extraction and PCR amplification of partial VP2 gene} Viral DNA from fecal samples of infected and healthy dogs was extracted as described by [15]. To reduce the residual effect of DNA polymerase activity inhibitors the supernatants were diluted to a ratio of 1:10 using distilled water. A single step polymerase chain reaction (PCR) was performed to amplify viral DNA from clinical specimens. Gene specific primer pair Hfor/Hrev [16] were used to amplify $630 \mathrm{bp}$ fragment of the capsid protein gene (VP2). The PCR-amplification of partial VP2 gene was carried out using 100 ng template DNA, in PCR mix as described earlier [16]. The PCR amplified products were run on $1.0 \%$ agarose gel containing ethidium bromide in Tris acetate EDTA (TAE) buffer and then visualized under UV transilluminator (Syngene, UK).

\section{Sequence and phylogenetic analysis}

PCR amplified fragments were cloned in pTZ57R/T vector (Fermentas) and completely sequenced by 
chain termination method of sequencing on automated sequencer Applied Biosystem 3100. Sequences were analyzed and assembled by the Lasergene DNA analysis package (v8; DNA-STAR Inc., Madison, WI, USA). Phylogenetic trees were generated, first by aligning the molecules using CLUSTAL-W, followed by Maximum likelihood method of phylogenetic tree construction with 1000 bootstrap replications in MEGA7 program [17]. MegAlign program in DNA STAR was used to produce pairwise comparisons for amino acid sequence similarities. The accession numbers for CPV and FPV isolated in this study are provided in Tables 1 and 2. The other viral sequences used for amino acid sequence comparisons and phylogenetic analyses were downloaded from GenBank. The branch lengths were measured in terms of the number of substitutions per site.

\section{Results and discussion}

CPV antigen detection and PCR amplification

From $40 \mathrm{CPV}$ suspected cases, fecal samples were collected and with the help of rapid immunochromatographic technique, 33 were found positive (82\%) while 7 were negative (17\%), 5 samples taken as negative control were found negative when analyzed using immunochromatographic technique. Of the total 33 positive samples, 25 samples, 75\% (25/33), were confirmed positive for $\mathrm{CPV}$ as a fragment of 630 bp was amplified in all 25 samples. Amplified product from all samples were successfully cloned in pTZ57R/T (Fermentas) vector and completely sequenced.

\section{Sequencing analysis of CPV from Pakistan}

VP2 gene amplified from representative isolates (total of 25) selected from diverse geographical locations of

Table 1 Details of samples sequenced, place and location, year of collection, gene bank accessions and mutations at various amino acid residues on partial VP2 protein of Canine parvovirus detected from dogs. The positions of mutations is based on CPV-2 GenBank accession number M38245, AY742953

\begin{tabular}{|c|c|c|c|c|c|c|c|c|}
\hline \multirow[t]{2}{*}{ S. No } & \multirow{2}{*}{$\begin{array}{l}\text { Sample No/ } \\
\text { Year of collection }\end{array}$} & \multirow{2}{*}{$\begin{array}{l}\text { Gene bank } \\
\text { Accession } \\
\text { numbers }\end{array}$} & \multirow{2}{*}{$\begin{array}{l}\text { Place of } \\
\text { collection }\end{array}$} & \multicolumn{4}{|c|}{ CPV genome nucleotide/amino acid positions and mutations } & \multirow[t]{2}{*}{ CPV type } \\
\hline & & & & $\begin{array}{l}3675 / 297 \\
\text { ( } T \text { to } G \text { ) }\end{array}$ & $\begin{array}{l}3756-3757 / 324 \\
\text { (TA to AT) }\end{array}$ & $\begin{array}{l}\text { 4062-4064/426 } \\
\text { (AAT to GAT/GAA) }\end{array}$ & $\begin{array}{l}4105-4106 / 440 \\
\text { (AC to GC) }\end{array}$ & \\
\hline 1 & 01CPV2a15/2014 & MF182906 & Faisalabad & G & AT & GAT & GC & New2a (Ser297 $\rightarrow$ Ala) \\
\hline 2 & 04CPV2a15/2014 & MF182907 & Faisalabad & G & AT & GAT & GC & New2a (Ser297 $\rightarrow$ Ala) \\
\hline 3 & 05CPV2a15/2014 & MF182908 & Faisalabad & G & AT & GAT & GC & New2a (Ser297 $\rightarrow$ Ala) \\
\hline 4 & 06CPV2a15/2014 & MF182909 & Faisalabad & G & AT & GAT & GC & New2a (Ser297 $\rightarrow$ Ala) \\
\hline 5 & 07CPV2a15/2014 & MF182910 & Faisalabad & G & AT & GAT & GC & New2a (Ser297 $\rightarrow$ Ala) \\
\hline 6 & 09CPV2a15/2014 & MF182911 & Faisalabad & G & AT & GAT & GC & New2a (Ser297 $\rightarrow$ Ala) \\
\hline 7 & 13CPV2a15/2014 & MF182912 & Faisalabad & G & AT & GAT & GC & New2a (Ser297 $\rightarrow$ Ala) \\
\hline 8 & 14CPV2a15/2014 & MF182913 & Faisalabad & G & AT & GAT & GC & New2a (Ser297 $\rightarrow$ Ala) \\
\hline 9 & 15CPV2a15/2014 & MF182914 & Faisalabad & G & AT & GAT & $A C$ & New2a (Ser297 $\rightarrow$ Ala) \\
\hline 10 & 16CPV2a15/2015 & MF182915 & Faisalabad & G & AT & GAT & GC & New2a (Ser297 $\rightarrow$ Ala) \\
\hline 11 & 17CPV2a15/2015 & MF182916 & Faisalabad & G & AT & GAT & GC & New2a (Ser297 $\rightarrow$ Ala) \\
\hline 12 & 18CPV2a15/2015 & MF182917 & Faisalabad & G & AT & GAT & GC & New2a (Ser297 $\rightarrow$ Ala) \\
\hline 13 & 19CPV2a15/2015 & MF182918 & Faisalabad & G & AT & GAT & GC & New2a (Ser297 $\rightarrow$ Ala) \\
\hline 14 & 20CPV2a15/2015 & MF182919 & Faisalabad & G & AT & GAT & $A C$ & New2a (Ser297 $\rightarrow$ Ala) \\
\hline 15 & 21CPV2a15/2015 & MF182920 & Faisalabad & G & AT & GAT & GC & New2a (Ser297 $\rightarrow$ Ala) \\
\hline 16 & 23CPV2a15/2015 & MF182921 & Faisalabad & G & AT & GAT & $A C$ & New2a (Ser297 $\rightarrow$ Ala) \\
\hline 17 & 24CPV2a15/2015 & MF182922 & Faisalabad & G & AT & GAT & GC & New2a (Ser297 $\rightarrow$ Ala) \\
\hline 18 & 25CPV2a15/2015 & MF182923 & Faisalabad & G & AT & GAT & GC & New2a (Ser297 $\rightarrow$ Ala) \\
\hline 19 & 26CPV2a15/2015 & MF182924 & Faisalabad & G & AT & GAT & GC & New2a (Ser297 $\rightarrow$ Ala) \\
\hline 20 & 28CPV2a15/2015 & MF182925 & Faisalabad & G & AT & GAT & GC & New2a (Ser297 $\rightarrow$ Ala) \\
\hline 21 & 32CPV2a15/2015 & MF182926 & Faisalabad & G & AT & GAT & GC & New2a (Ser297 $\rightarrow$ Ala) \\
\hline 22 & 33CPV2a15/2015 & MF182927 & Faisalabad & G & AT & GAT & GC & New2a (Ser297 $\rightarrow$ Ala) \\
\hline 23 & 34CPV2a15/2015 & MF182928 & Faisalabad & G & AT & GAT & GC & New2a (Ser297 $\rightarrow$ Ala) \\
\hline 24 & 38CPV2a15/2015 & MF182929 & Faisalabad & G & AT & GAT & $A C$ & New2a (Ser297 $\rightarrow$ Ala) \\
\hline 25 & 39CPV2a15/2015 & MF182930 & Faisalabad & G & AT & GAT & $A C$ & New2a (Ser297 $\rightarrow$ Ala) \\
\hline
\end{tabular}


Table 2 Details of samples sequenced, place and location, year of collection, gene bank accessions and mutations at position of amino acid residues on partial VP2 protein of Canine parvovirus and FPV detected from dogs

\begin{tabular}{|c|c|c|c|c|c|c|c|c|c|}
\hline \multirow[t]{2}{*}{ S. No } & \multirow{2}{*}{$\begin{array}{l}\text { Sample No/ } \\
\text { Year of collection }\end{array}$} & \multirow{2}{*}{$\begin{array}{l}\text { Gene bank } \\
\text { Accession numbers }\end{array}$} & \multirow{2}{*}{$\begin{array}{l}\text { Place of } \\
\text { collection }\end{array}$} & \multicolumn{5}{|c|}{ Amino acid positions } & \multirow[t]{2}{*}{ Serotype } \\
\hline & & & & 297 & 300 & 305 & 375 & 426 & \\
\hline 1 & 10FPV15/2014 & MF182903 & Faisalabad & Ala & Gly & Tyr & Asp & Asn & FPV \\
\hline 2 & 11FPV15/2014 & MF182904 & Faisalabad & Ala & Gly & Tyr & Asp & Asn & FPV \\
\hline 3 & 13FPV15/2014 & MF182905 & Faisalabad & Ala & Gly & Tyr & Asp & Asn & FPV \\
\hline 4 & FPV-314 & D78585 & & Ala & Gly & Tyr & Asp & Asn & FPV \\
\hline 5 & 07CPV2a15/2014 & MF182910 & Faisalabad & Ser & Gly & Tyr & Asp & Asn & New2a (Ser297 $\rightarrow$ Ala) \\
\hline 6 & 09CPV2a15/2014 & MF182911 & Faisalabad & Ser & Gly & Tyr & Asp & Asn & New2a (Ser297 $\rightarrow$ Ala) \\
\hline 7 & 13CPV2a15/2014 & MF182912 & Faisalabad & Ser & Gly & Tyr & Asp & Asn & New2a (Ser297 $\rightarrow$ Ala) \\
\hline 8 & CPV-16 & M24003 & & Ser & Gly & Tyr & Asp & Asn & New2a (Ser297 $\rightarrow$ Ala) \\
\hline
\end{tabular}

district Faisalabad was partially sequenced. After sequencing BLAST analysis showed 25 sequences from 25 different samples as the CPV new $2 \mathrm{a}$ variant and 3 sequences from 3 different samples, as the FPV. Three samples in which FPV was identified were also infected with the new CPV-2a variant. Of the 25 samples in which VP2 was amplified $100 \%(25 / 25)$ confirmed sequences with CPV 2a new variant and in $12 \%(3 / 25)$ sequences of FPV were identified. The partial VP2 nucleotide sequences from this study were analyzed using DNASTAR software, revealing homologies of 99.5-99.9\% and $99.9 \%$ within the new CPV-2a strain solates and between the FPV isolates, previously reported from Asiatic region, mainly China and Europe. Similarly low nucleotide sequence similarity between the reference CPV 2a strain (AY742953), FPV (M38246) and CPV new 2a, FPV strains isolated in this study was found. All new CPV-2a clones had a nucleotide substitution at position 3675 (T-G); 3685 (C-G) and an identical nucleotide $(\mathrm{T})$ at position 4064 (Table 1), which are characteristics of nucleotide variations of new CPV-2a (CPV-2a with nucleotide variation T-G at position 3675 or CPV-2a with amino acid variation Ser297-Ala). Multiple amino acid sequence alignment was performed to find sequence homology of the prevalent strains with each other and with reference CPV 2a (M24003), and a new CPV-2a (AY742953) and FPV (M38246) strains. Based on the amino acid residue at the 426 position of the VP2 gene, the isolates were classified into CPV-2a type (426-Asn) (Table 1). Additional amino acid changes were also found at 324 and 440 positions of the VP2 gene (Table 1). All of the new CPV 2a isolates in the present study had amino acid substitution Ser297Ala in VP2 (Table 1), indicating that the isolates were either new CPV-2a or new CPV-2b. All the new CPV 2a isolates reported during 2014-2015 had amino acid Tyr324Ile substitution due to mutation of TAT to ATT of the VP2 gene (Table 1). Residue 324 is a part of an important antigenic epitope and has ability to alter viral biology; it is under positive selection pressure [13] and arising independently in different geographic locations. Sequence analysis showed that this mutant is predominant in Asian countries like Korea, China and India. Emergence of this new variant is attributed to possible importation of foreign strains or could be the evolution of the existing CPV-2a strain. Further investigations are required to distinguish between these two possibilities; else this particular viral variant may spread throughout the Pakistan in the coming years. The neighboring residue 323 , is known for binding to canine transferrin receptor TfR [18] along with residue 93 and have influence on viral host range and tissue tropism. Mutation in residue 323 from Asn to Asp causes changes in interactions between residues of elaborated loops within the same VP2 molecule or the other three fold VP2 molecule and hence could jeopardize virus multiplication in canine cells [19]. Twenty out of twenty-five isolates had an additional amino acid change 440 replacing Thr with Ala and further two out of those 20 isolates showed amino acid substitution Asp434Gly. Residue 440 gains the importance antigenically as it is present in GH loop of the VP2 protein which makes the surface of the virus capsid [20]. Residue 440 is present at the top of the three fold spike, which is considered to be the main antigenic site of the virus and also counts as one of the few VP sites that undergo positive selection [21]. Three isolate were found as Feline panleukopenia virus (Table 2), which mostly infects cats and cause gastroenteritis, was detected in three infected canine fecal samples. Previously it was known that two of CPV specific sequence amino acid at position 93-Asn and 323-Asn if introduced in FPV will allow it to multiply invitro canine cell line. These two amino acids along with 103-Val allow CPV to efficiently multiply in canine cells [19], but in the present study residue 323 remain FPV specific (Asp) and the remaining two amino acids were not determined in present sequence analysis. In addition, among the five amino acids in Table 2, the only difference between FPV and CPV from Pakistan as well as other 
regions is at the amino acid residue 297 (Ala in FPV and Ser in CPV isolate). On the other side, a study have shown that in-vivo inoculation of the FPV in dogs, unexpectedly enabled the virus to replicate in thymus and bone marrow cells but not in the intestine or mesenteric lymph nodes [22]. But, a recombinant virus of CPV and FPV was shown to multiply in high titers in canine intestine and mesenteric lymph nodes [23]. Two non-synonymous mutations, found in the present study, resulting in amino acid change Thr390Ala in (FPV sequence MF182903), Asp434Gly in (New CPV-2a sequence MF182909, MF182911, MF182917), which were previously not been reported in any other country.

\section{Phylogenetic analysis}

Maximum likelihood method was used to construct phylogenetic tree to determine the evolutionary relationship of our analyzed new CPV-2a strains with other strains of different geological areas along with vaccine strains. Three strains of FPV comprising $630 \mathrm{bp}$ of partial VP2 gene from Pakistan along with other FPV strains of different geological areas were also included in the tree (Fig. 1). The parvoviruses sequenced in this study clustered in three different monophyletic clades in the phylogenetic tree at the antigenic region of VP2 gene though there is a very high sequence similarity among these sequences (Fig. 1). Total 25 isolates from 2014 to 15 , could be typed as new CPV- 2a strains as shown in Fig. 1. These strains appeared to cluster with other CPV isolates from China, India, Japan, Thailand and Uruguay. These observations suggest that CPV-2a in Pakistan has maximum similarity with other strains of Asiatic origin. High nucleotides similarity between Indian, Chinese and Pakistani isolates of CPV-2a is an indication that this disease is endemic in the region. High nucleotides similarity with Indian isolates is not surprising, because there are similar environmental conditions in both the countries and it remained the same region for centuries. New CPV-2a isolates clustered with isolates of $2 \mathrm{a}$ or new $2 \mathrm{a}$ types from India, Uruguay and China. Thus the important observation, which is inferred from this phylogenetic analysis is that, the recent CPV isolates are clustering away from the commercial vaccine strains. Interestingly three FPV strains showed immediate ancestral relationship with viral strain reported from USA, Asia and Europe. The close clustering with these isolates suggests that FPV is highly conserved and should be addressed at global level. The mixed infection of FPV and CPV is surprising and interesting, as it has not been previously reported. The interesting observation is that the FPV alone was not detected in any of the samples. It was only detected in CPV positive samples. So, it might be possible that FPV was somehow supported by CPV. FPV alone might not be able to replicate in dogs. Further detailed experimentation

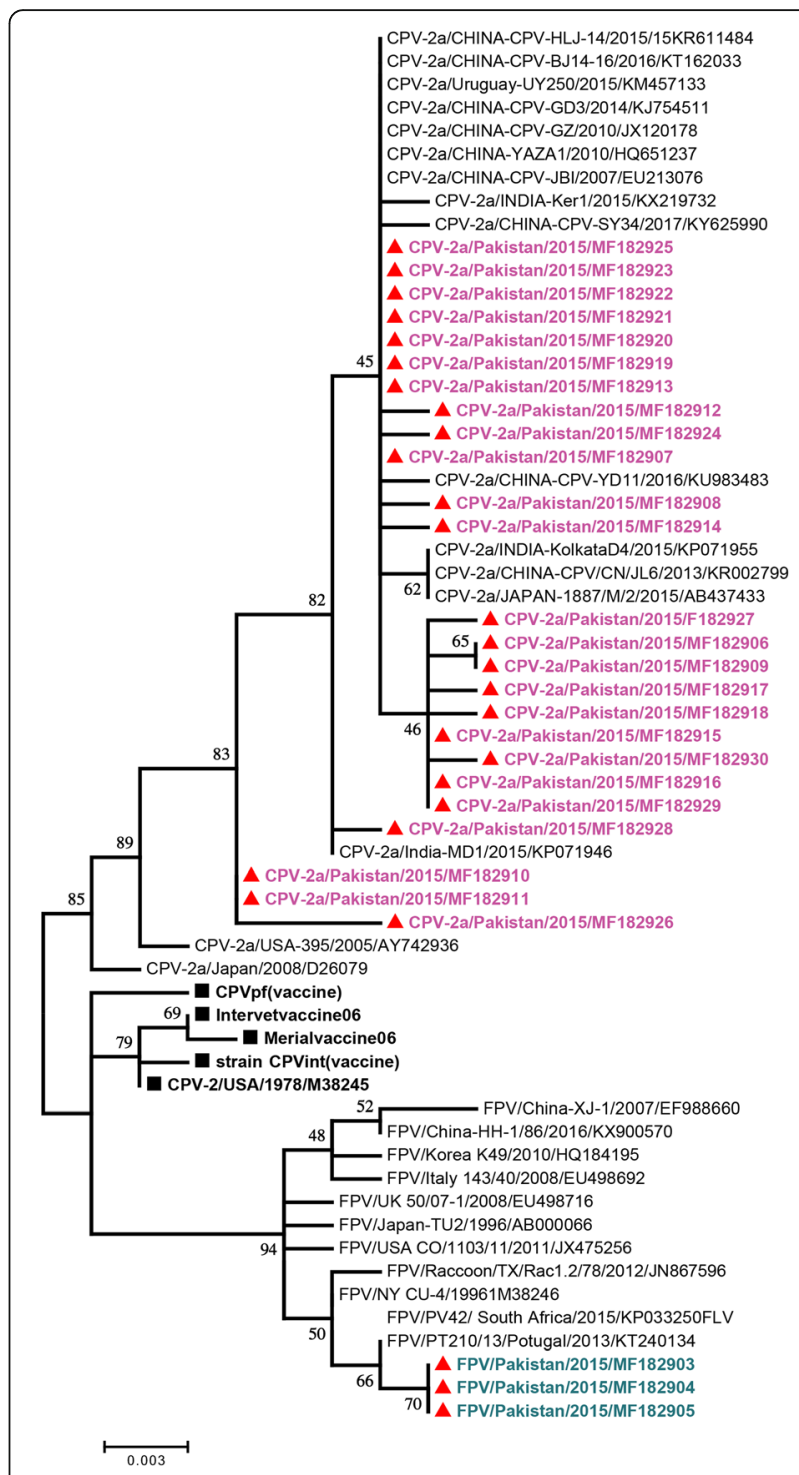

Fig. 1 Maximum likelihood tree depicting phylogenetic relationship between CPV and FPV isolates from Pakistan and other geographical locations. Parvoviruses obtained from dogs sequenced in this study are shown with red triangles. Isolates with pink color show (CPV) and bold green colors show (FPV). The vaccine strains are shown with black squares. Bootstrap values are shown next to the branches in the phylogenetic tree

is required to explain this phenomenon. There is another possibility to explain this observation. Dogs analyzed in this study were stray animals and due to coprophagous behavior in dogs it is very much likely that FPV detection was due to faeces ingestion and they are of no clinical relevance. However, further experiments are needed to support this observation.

\section{Conclusions}

To date, there are no studies available on the clinical course and prognosis of cases presenting CPV-FPV dual 
infection. In this study CPV and FPV are detected in rectal swab samples of three dogs. We are not sure that whether presence of these two viruses together is just by chance or have some scientific relevance. If this is a true co-infection then we need to be very careful to study the epidemiology of these viruses. Analogous to what happens in the presence of multiple human infections [24], the clinical course of parvovirus infection could be altered and CPV could accelerate the progression of panleukopenia infection, since FPV represents a novel pathogen for dogs or vice versa. Alternatively, CPV-FPV co-infection could have a direct implication for virus persistence, host-viral interaction and pathogenesis [25]. As already discussed presence of these viruses together in rectal swab samples could be due to coprophagous behavior of dogs and FPV detection was due to faeces ingestion and they are of no clinical relevance. However, further sophisticated experiments are needed to support this observation.

\section{Abbreviations}

BLAST: Basic local alignment search tool; CL: Color line; CPV: Canine parvovirus; FPV: Feline panleukopenia virus; MEV: Mink enteritis virus; PBS: Phosphate buffer saline; PCR: Polymerase chain reaction; RaPV: Raccoon parvovirus; TAE: Tris-acetate-EDTA; TL: Test line

\section{Acknowledgements}

We acknowledge all members of virology lab for help and support to perform experiments for this work.

\section{Funding}

This work was funded by the IFS Research Grant No. C/5260-1 to Dr Muhammad Mubin and IFS Research grant No. C/5434-1 to Dr Muhammad Shah Nawaz ul Rehman.

\section{Availability of data and materials}

The datasets used and/or analyzed during the current study are available from the corresponding author on reasonable request.

\section{Authors' contributions}

NA MM MSNR and AQ conceived the idea. AR, ZZ, SI and MS performed the experiments; NA, AR and ZZ wrote the paper. MM MSNR and $A Q$ edited the final manuscript. All authors read and approved the final manuscript.

\section{Ethics approval and consent to participate}

Not Applicable.

\section{Consent for publication}

Not Applicable.

\section{Competing interests}

The authors declare that they have no competing interests.

\section{Publisher's Note}

Springer Nature remains neutral with regard to jurisdictional claims in published maps and institutional affiliations.

\section{Author details}

${ }^{1}$ Virology Lab, Center of Agricultural Biochemistry and Biotechnology (CABB), University of Agriculture, PO Box 38040, Jail road, Faisalabad 38000, Pakistan. ${ }^{2}$ Department of Infection and Immunity, Research Center, King Faisal Specialist Hospital and Research Center, Riyadh, Saudi Arabia. ${ }^{3}$ Department of Microbiology and Immunology, Alfaisal University School of Medicine, Riyadh, Saudi Arabia. ${ }^{4}$ Department of Clinical Medicine and Surgery, University of Agriculture, Faisalabad, Pakistan.
Received: 6 September 2017 Accepted: 7 March 2018

Published online: 15 March 2018

\section{References}

1. Hoelzer K, Shackelton LA, Holmes EC, Parrish CR. Within-host genetic diversity of endemic and emerging parvoviruses of dogs and cats. J Virol. 2008:82:11096-105.

2. Berns Kl, Bergoin M, Bloom M, Lederman M, Muzyczka N, Siegl G, Tal J, Tattersall P. Family parvoviridae. In: van Regenmortel FCM, DHL B, Carstens EB, Estes MK, Lemon SM, Maniloff J, Mayo MA, DJ MG, Pringle CR, Wickner $\mathrm{RB}$, editors. Virus taxonomy, classification and nomenclature of viruses. New York: Academic Press; 2000. p. 311-23.

3. Organtini $\sqcup$, Allison AB, Lukk T, Parrish CR, Hafenstein S. Global displacement of canine parvovirus by a host-adapted variant. Structural comparison between pandemic viruses with distinct host ranges. J Virol. 2015;89:1909-12.

4. Hong C, Decaro N, Desario C, Tanner P, Pardo MC, Sanchez S, Buonavoglia C, Saliki JT. Occurrence of canine parvovirus type 2C in the United States. J Vet Diagn Investig. 2007;19:535-9.

5. Clegg S, Coyne K, Dawson S, Spibey N, Gaskell R, Radford A. Canine parvovirus in asymptomatic feline carriers. Vet Microbiol. 2012;157:78-85.

6. Decaro N, Buonavoglia D, Desario C, Amorisco F, Colaianni ML, Parisi A, Terio V, Elia G, Lucente MS, Cavalli A. Characterisation of canine parvovirus strains isolated from cats with feline panleukopenia. Res Vet Sci. 2010;89:275-8.

7. Battilani M, Gallina L, Vaccari F, Morganti L. Co-infection with multiple variants of canine parvovirus type 2 (CPV-2). Vet Res Commun. 2007;31

8. Battilani M, Scagliarini A, Ciulli S, Morganti L, Prosperi S. High genetic diversity of the VP2 gene of a canine parvovirus strain detected in a domestic cat. Virology. 2006;352:22-6.

9. Gottschalck E, Alexandersen S, Cohn A, Poulsen L, Bloom M, Aasted B. Nucleotide sequence analysis of Aleutian mink disease parvovirus shows that multiple virus types are present in infected mink. J Virol. 1991;65:4378-86.

10. Vieira MJ, Silva E, Desario C, Decaro N, JI C, Buonavoglia C, Thompson G. Natural coinfection with 2 parvovirus variants in dog. Emerg Infect Dis. 2008; 14:678

11. Decaro N, Elia G, Desario C, Roperto S, Martella V, Campolo M, Lorusso A, Cavalli A, Buonavoglia C. A minor groove binder probe real-time PCR assay for discrimination between type 2-based vaccines and field strains of canine parvovirus. J Virol Methods. 2006;136:65-70.

12. Parrish CR, Aquadr CF, Strassheim M, Evermann J, Sgro J, Mohammed H Rapid antigenic-type replacement and DNA sequence evolution of canine parvovirus. J Virol. 1991;65:6544-52.

13. Hoelzer K, Shackelton LA, Parrish CR, Holmes EC. Phylogenetic analysis reveals the emergence, evolution and dispersal of carnivore parvoviruses. J Gen Virol. 2008;89:2280-9.

14. Shabbir MZ, Sohail MU, Chaudhary UN, Yaqub W, Rashid I, Saleem MH, Munir M. Genetic characterization of canine parvovirus from dogs in Pakistan. Acta Virol. 2017;61:175-82

15. Schunck B, Kraft W, Truyen U. A simple touch-down polymerase chain reaction for the detection of canine parvovirus and feline panleukopenia virus in feces. J Virol Methods. 1995:55:427-33.

16. Buonavoglia C, Martella V, Pratelli A, Tempesta M, Cavalli A, Buonavoglia D, Bozzo G, Elia G, Decaro N, Carmichael L. Evidence for evolution of canine parvovirus type 2 in Italy. J. Gen. Virol. 2001;82:3021-5.

17. Tamura K, Dudley J, Nei M, Kumar S. MEGA4: molecular evolutionary genetics analysis (MEGA) software version 4.0. Mol. Biol. Evolution. 2007;24:1596-9.

18. Hueffer K, Parker JS, Weichert WS, Geisel RE, Sgro JY, Parrish CR. The natural host range shift and subsequent evolution of canine parvovirus resulted from virus-specific binding to the canine transferrin receptor. J Virol. 2003; 77:1718-26.

19. Chang SF, Sgro JY, Parrish CR. Multiple amino acids in the capsid structure of canine parvovirus coordinately determine the canine host range and specific antigenic and hemagglutination properties. J Virol. 1992;66:6858-67.

20. Battilani M, Ciulli S, Tisato E, Prosperi S. Genetic analysis of canine parvovirus isolates (CPV-2) from dogs in Italy. Virus Res. 2002;83:149-57.

21. Tsao J, Chapman MS, Agbandje M, Keller W, Smith K, Wu H, Compans RW. The three-dimensional structure of canine parvovirus and its functional implications. J Sci. 1991;251:1456-64.

22. Truyen U, Parrish C. Canine and feline host ranges of canine parvovirus and feline panleukopenia virus: distinct host cell tropisms of each virus in vitro and in vivo. J Virol. 1992;66:5399-408. 
23. Parrish CR. Mapping specific functions in the capsid structure of canine parvovirus and feline panleukopenia virus using infectious plasmid clones. Virology. 1991;183:195-205.

24. Miyazawa T, Ikeda Y, Nakamura K, Naito R, Mochizuki M, Tohya Y, Vu D, Mikami T, Takahashi E. Isolation of feline parvovirus from peripheral blood mononuclear cells of cats in northern Vietnam. Microbiol Immunol. 1999;43: 609-12.

25. Zhang P, Sandland GJ, Feng Z, Xu D, Minchella DJ. Evolutionary implications for interactions between multiple strains of host and parasite. J Theor Biol. 2007;248:225-40.

Submit your next manuscript to BioMed Central and we will help you at every step:

- We accept pre-submission inquiries

- Our selector tool helps you to find the most relevant journal

- We provide round the clock customer support

- Convenient online submission

- Thorough peer review

- Inclusion in PubMed and all major indexing services

- Maximum visibility for your research

Submit your manuscript at www.biomedcentral.com/submit
Biomed Central 